\title{
Reconstruction of Quaternary temperature fields and model-data comparison
}

Norbert KüHL ${ }^{1}$, C. Gebhardt ${ }^{2}$, F. Kaspar ${ }^{2}$, A. Hense ${ }^{3}$ ANd T. LitT ${ }^{1}$

'Steinmann Institute of Geology, Mineralogy and Paleontology, University of Bonn, Germany; kuehl@uni-bonn.de 2Deutscher Wetterdienst (German National Meteorological Service), Offenbach

${ }^{3}$ Meteorological Institute, University of Bonn, Germany

Model-data comparisons for paleoclimatic periods are one way to increase the confidence in climate system models, which are, for example, used to simulate projections of future climate change. The last interglacial, the Eemian ( 127-116 kyr BP), is an example of a warm period that came to a natural end and a period in which human influence was literally absent. The fact that many sites exist in Europe, where the Eemian has been well investigated, adds to the attractiveness of this period for spatial reconstructions and for model-data comparisons. Model-data comparisons, however, are challenged by the use of data on different spatial scales. Conventional reconstruction methods provide local reconstructions for individual sites, although these results may be biased by characteristics of the local environment. This often hampers a proper comparison with climate models, and hence their validation, because these local effects are mostly attributable to scales too small to be resolved by climate models. A variational approach (Gebhardt et al., 2008) connects the different scales by an upscaling of the local paleoinformation, together with a dynamically consistent spatial smoothing.

\section{Probabilistic reconstruction and variational approach}

Paleobotanical fossils (such as pollen and plant macrofossils) provide well-established terrestrial proxies used for quantitative climate reconstructions. Various approaches exist to transfer the paleobotanical data into reconstructed climate (e.g., Birks and Birks, 2003). Probabilistic reconstruction methods can take into account the uncertainties inherent in the fossil record and enable clarification of the relationship between climate and individual taxa. They potentially include all taxa, can be multivariate, and allow for an estimation of the reconstruction error. The relationship between climate and individual taxa can be described by probability density functions. For example, combining transfer functions of several co-occurring taxa provides the most probable climate reconstruction and its range of uncertainty (Kühl et al., 2002).

An approach that accounts for the difference in local proxy-reconstructions and large-scale climate simulations is the reconstruction of climate parameters as spatially coherent fields on scales comparable to those resolved by typical climate system

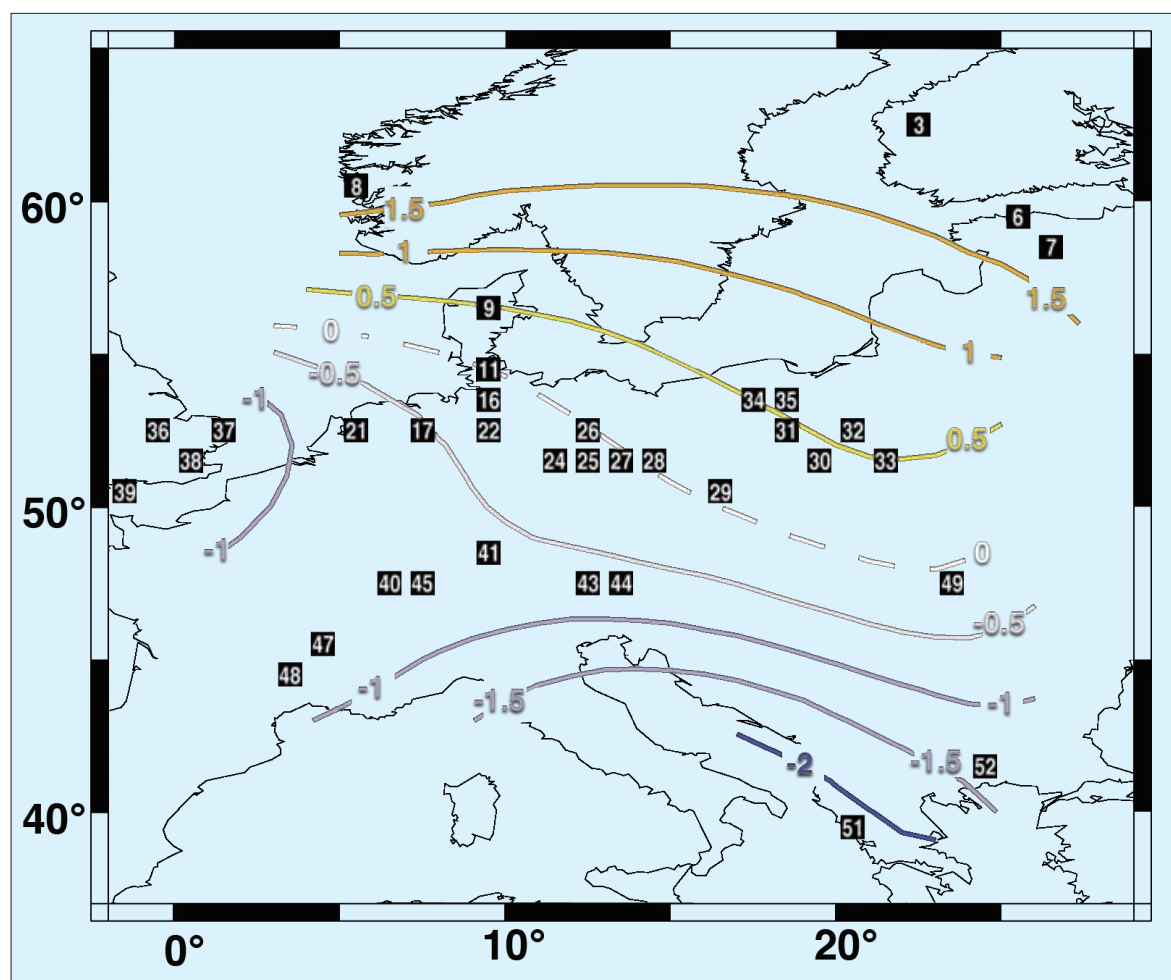

Figure 1: January temperature anomalies between the modern climate (1961-1990, New et al., 2000) and those reconstructed for the Corylus-phase (Pollen Assemblage Zone 4a) of the Eemian interglacial (Gebhardt et al., 2008). The contour interval is $0.5^{\circ} \mathrm{C}$. The numbers in black boxes refer to site locations for which detailed information can be found in Gebhardt et al. (2008). models (Gebhardt et al., 2008). The variational analysis by Gebhardt et al. (2008) combines the probabilistic reconstruction method of Kühl et al. (2002) with a dynamical constraint (with a simple yet efficient model of the underlying climate physics) on the reconstructed climate parameter. The core of such a variational method is a cost function (Le Dimet and Talagrand, 1986), which mathematically takes into account all paleobotanical information, and climate physics information, in the reconstruction.

Our cost function for the reconstruction of temperature fields consists of two parts. The aim is to minimize the sum of these parts, i.e. the "costs" of the reconstruction. Both parts are a function of the deviation of the Eemian temperature field from the 1961-1990 climatology developed by New et al. (2000). The proxy data, in this case botanical fossil remains, form the basis of the vegetational part of the cost function. Statistical transfer functions translate the potential Eemian temperature field at a fossil site to a probability of the paleo-occurrence of the observed fossil record. The higher this probability, the lower the costs of this vegetational part in the cost function.

The second part quantifies the deviation of the potential Eemian temperature field from a simple dynamical constraint, which serves to capture the main climatological characteristics of large-scale temperature anomalies (Klaßen et al., 1994; Hense et al., 1990). The main purpose of this constraint is to stabilize the reconstruction by constraining the spatial structures of the Eemian temperature anomalies to climatologically relevant scales but not their amplitudes.

The temperature field for which the cost function is minimized, i.e., for which the cost function calculates lowest costs, is the one that is most consistent with all available information (Fig. 1) and is interpreted as the most likely Eemian temperature field. All mathematical details of the cost function are described in Gebhardt et al. (2008).

\section{Data-model comparison}

Reconstructed January and July mean temperatures of the early Eemian ( 125 kyr BP) have errors with a median value of about 


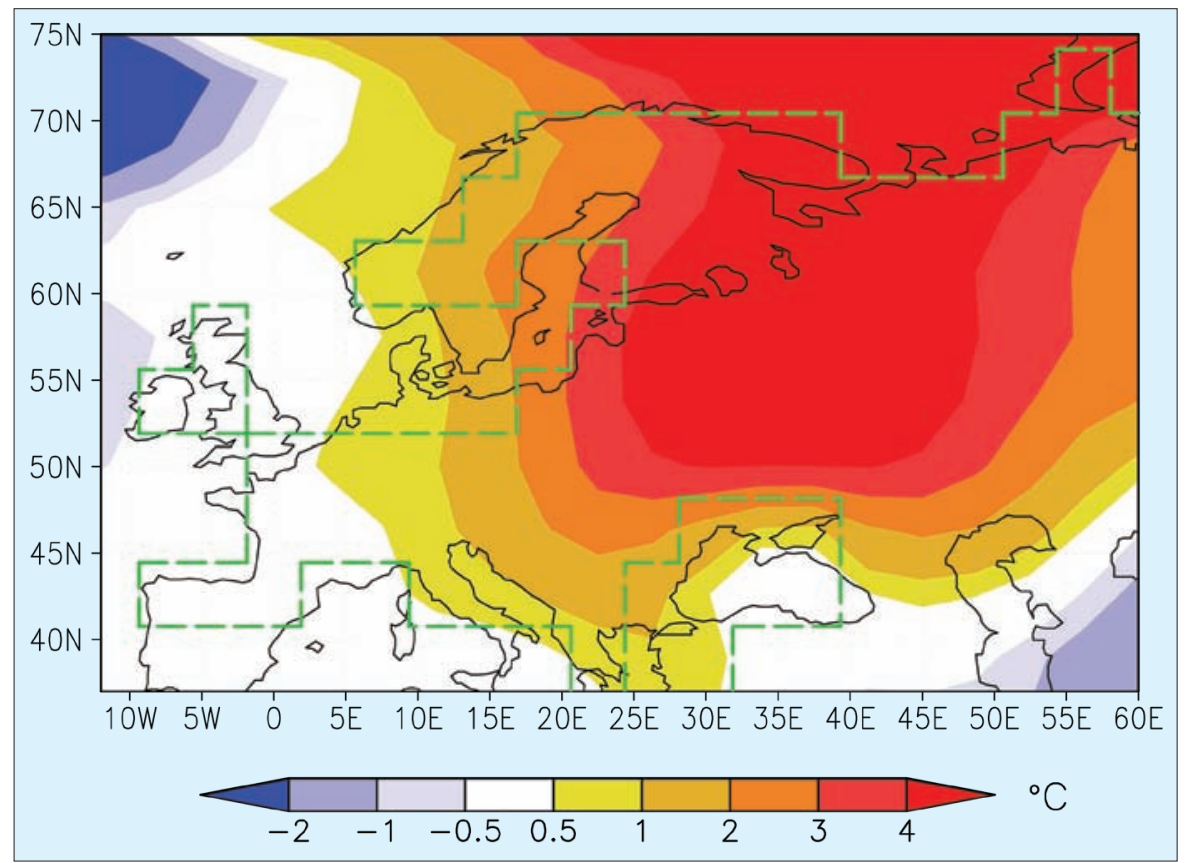

Figure 2: January temperature anomalies as simulated by the coupled ocean atmosphere general circulation model ECHO-G for the Eemian at $125 \mathrm{kyr}$ BP minus preindustrial, averaged over a 50-year interval. The land mask of the model is shown with green dashed lines to illustrate the spatial resolution of the model (Kaspar et al., 2005).

$1.8^{\circ} \mathrm{C}$ in January and about $1.1^{\circ} \mathrm{C}$ in July. Reconstructions across Europe show positive temperature anomalies for Scandinavia and near the east coast of the Baltic Sea. In contrast, early Eemian temperatures in Central Europe were apparently quite similar to those found today, as no drastic differences were reconstructed between the Eemian and modern (1961-1990) climate. This implies somewhat stronger temperature gradients across Europe in the Eemian than are observed today (Fig. 1) (Gebhardt, 2003; Kühl, 2003).

A gradient in simulated January temperature anomalies is also visible for that region in a climate simulation (Kaspar et al., 2005) using the coupled climate model ECHO-G (Min et al., 2005), which was driven by orbitally-induced changes in insolation (Fig. 2). The model consists of the ECHAM4 atmosphere model at a horizontal resolution of $\sim 3.75^{\circ}$ and 19 vertical levels, coupled with the HOPE-G ocean model at $\sim 2.8^{\circ}$ and a gradual meridional refinement toward the equator to $0.5^{\circ}$.

The temperatures in Western Europe (Spain, France) are similar in the simulation of the Eemian interglacial and of the preindustrial period. Increasing temperature differences between both simulations occur in the northeast direction toward Scandinavia. In the region of Finland, the temperature anomalies are in the order of $+3^{\circ} \mathrm{C}$. The general pattern is consistent with the results of the reconstruction, and model and reconstructions only differ in the magnitude of deviation between Eemian and today's climate.

The overall similarity in the pattern supports the conclusion drawn in Kaspar et al. (2005) that the same processes are responsible for the spatial distribution in the simulation and in the estimates from the paleoecological data. The winter temperature anomalies cannot be explained by insolation change directly because the winter insolation in the high northern latitudes was lower in the Eemian than today. Therefore, it can only explain the Western European temperature differences.

Two effects contribute to the increasingly positive differences toward Scandinavia: First, increased westerly winds at around $55^{\circ} \mathrm{N}$ transport more oceanic heat into this region. Second, the winter sea ice in the Arctic is significantly reduced, especially in the Barents Sea. This causes a strong reduction in the surface albedo, resulting in significantly increased regional temperatures. The decreased sea ice coverage is mainly a result of the distinct increase in northern hemispheric summer insolation, which is not compensated for by reduced winter insolation. These results illustrate that changes in insolation and the reaction of the atmosphere-ocean system, as simulated by the climate model, are sufficient to explain the reconstructed European temperature patterns.

Although it has to be noted that the reference period for calculating anomalies for the reconstruction (1961-90) and the ECHO-G simulation (1871-1900) are different, the offset due to climate change is small in winter and with weak gradients in summer (Min and Hense, 2007). Thus, there is no effect on the conclusion about orbitally induced influence. The results are in line with previous modeling studies (e.g., Felis et al., 2004). More results of the ECHO-G simulations and comparisons with other studies can be found in Kaspar and Cubasch (2007).

Even though there are model-data comparisons that show good correspondence between local reconstructions and model simulations (e.g., Kaspar et al., 2005), the large-scale properties of the reconstructed anomaly fields is certainly more suitable for comparisons of proxy-based reconstructions with simulated paleoclimates because their spatial resolution and consistency are closer to the properties of the model simulations.

\section{References}

Felis, T., Lohmann, G., Kuhnert, H., Lorenz, S.J., Scholz, D., Pätzold, J., AlRousan, S.A. and Al-Moghrabi, S.M., 2004: Increased seasonality in Middle East temperatures during the last interglacial period, Nature, 429: 164-168.

Gebhardt, C., Kühl, N., Hense, A. and Litt, T., 2008: Reconstruction of Quaternary temperature fields by dynamically consistent smoothing, Climate Dynamics, 30: 421-437.

Kaspar, F., Kühl, N., Cubasch, U. and Litt, T., 2005: A model-data-comparison ofEuropean temperatures in the Eemian interglacial, Geophysical Research Letters, 32: L11703, doi:10.1029/2005GL022456.

Kühl, N., Gebhardt, C., Litt, T. and Hense, A., 2002: Probability Density Functions as Botanical-Climatological Transfer Functions for Climate Reconstruction, Quaternary Research, 58: 381-392.

Le Dimet, F.-X. and Talagrand, 0., 1986: Variational algorithms for analysis and assimilation of meteorological observations: theoretical aspects, Tellus, 38A: 97-110.

For full references please consult:

www.pages-igbp.org/products/newsletter/ref2008_2.html 